\title{
Deoxyribonucleic Acid Hybridization Study of Methanogenium and Methanocorpusculum Species, Emendation of the Genus Methanocorpusculum, and Transfer of Methanogenium aggregans to the Genus Methanocorpusculum as Methanocorpusculum aggregans comb. nov.
}

\author{
LUYING XUN, ${ }^{1}$ DAVID R. BOONE, ${ }^{2}$ AND ROBERT A. MAH ${ }^{1 *}$ \\ School of Public Health, University of California, Los Angeles, California $90024,{ }^{1}$ and Environmental Science and \\ Engineering, Oregon Graduate Center, Beaverton, Oregon 97006-1999²
}

\begin{abstract}
Deoxyribonucleic acid hybridization indicated that species of the genera Methanogenium and Methanocorpusculum are phylogenetically diverse. The 10 strains examined in this study fall into four phylogenetically defined groups. The first group (Methanogenium marisnigri, Methanogenium bourgense, Methanogenium olentangyi, and Methanogenium thermophilicum) is physiologically the most diverse, containing mesophiles and thermophiles and containing marine and nonmarine organisms. The second group (Methanogenium aggregans, Methanocorpusculum parvum, and Methanocorpusculum labreanum) contains very small mesophilic coccoid organisms from anaerobic digestors. The third group contains a single species, Methanogenium tationis, which was isolated from a solfataric mud pool, and the fourth group contains the type species, Methanogenium cariaci, which is a marine organism. Based on the high deoxyribonucleic acid sequence similarity between Methanogenium aggregans and Methanocorpusculum parvum, we propose to transfer Methanogenium aggregans to the genus Methanocorpusculum, naming it Methanocorpusculum aggregans comb. nov. The type strain is strain MSt (= DSM $3027=$ OGC 21). The species in the other three major groups are placed in the genus Methanogenium, although the lack of phylogenetic relatedness indicates that some of these organisms should be separated from Methanogenium cariaci into new genera. However, we propose that cataloging or sequencing of ribosomal ribonucleic acid from these species must be completed before new genera are designated.
\end{abstract}

The genus Methanogenium was originally described as a group of irregularly coccoid, $\mathrm{H}_{2}$-utilizing, marine methanogens with low temperature optima $\left(20\right.$ to $\left.25^{\circ} \mathrm{C}\right)$ and guanineplus-cytosine $(\mathrm{G}+\mathrm{C})$ contents of 52 to $61 \mathrm{~mol} \%$. Several new coccoid, methanogenic species were assigned to this genus because their physiology and the $\mathrm{G}+\mathrm{C}$ contents of their deoxyribonucleic acids (DNAs) suggested that they were more closely related to Methanogenium than to the coccoid genus Methanococcus. However, the description of the genus Methanogenium was never formally emended to contain these species $(2,5,6,8,11,12)$. More recently, Methanocorpusculum was established as a new genus when $16 \mathrm{~S}$ ribosomal ribonucleic acid cataloging studies showed strong phylogenetic differences between Methanocorpusculum parvum and two species of Methanogenium, Methanogenium cariaci and Methanogenium marisnigri (12). However, Methanocorpusculum parvum was not compared with other Methanogenium species.

In this study we found that Methanogenium aggregans is phylogenetically closely related to Methanocorpusculum parvum. We also describe the DNA sequence similarities among species of Methanogenium and Methanocorpusculum.

(Some of the data have been presented previously [Xun, Boone, and Mah, Abstr. Annu. Meet. Am. Soc. Microbiol. 1988, abstr. I24, p. 185].)

\footnotetext{
* Corresponding author.
}

\section{MATERIALS AND METHODS}

Bacterial strains and growth conditions. Strains were obtained from the Deutsche Sammlung von Mikroorganismen (DSM) or from the Oregon Graduate Center Collection of Methanogenic Archaeobacteria (OGC). An attempt was made to obtain and include all extant Methanogenium and Methanocorpusculum strains. For the following strains our source of each strain is listed first in parentheses, followed by an alternate source in most cases (accession numbers are indicated): Methanocorpusculum labreanum $\mathrm{Z}^{\mathrm{T}}$ (OGC $1^{\mathrm{T}}$, DSM $\left.4855^{\mathrm{T}}\right)(\mathrm{T}=$ type strain), Methanocorpusculum parvum XII ${ }^{\mathrm{T}}$ (DSM $3823^{\mathrm{T}}$, OGC $63^{\mathrm{T}}$ ), Methanogenium aggregans $\mathrm{MSt}^{\mathrm{T}}$ (OGC $21^{\mathrm{T}}$, DSM $3027^{\mathrm{T}}$ ), Methanogenium bourgense $\mathrm{MS}^{\mathrm{T}}$ (OGC $15^{\mathrm{T}}$, DSM $3045^{\mathrm{T}}$ ), Methanogenium bourgense LX1 (OGC 24), Methanogenium cariaci JR1 ${ }^{\mathrm{T}}$ (DSM $1497^{\mathrm{T}}$, OGC $49^{\mathrm{T}}$ ), Methanogenium marisnigri JR1 ${ }^{\mathrm{T}}$ (DSM $1498^{\mathrm{T}}$, OGC $56^{\mathrm{T}}$ ), Methanogenium olentangyi $\mathrm{RC} /$ $\mathrm{ER}^{\mathrm{T}}$ (DSM $2772^{\mathrm{T}}$, OGC $52^{\mathrm{T}}$ ), Methanogenium tationis DSM $2702^{\mathrm{T}}$ (DSM $2702^{\mathrm{T}}$, OGC $\left.43^{\mathrm{T}}\right)$, and Methanogenium thermophilicum UCLA (OGC 6, DSM 2624). Methanogenium thermophilicum UCLA has approximately $100 \%$ DNA sequence similarity with Methanogenium thermophilicum $\mathrm{CR}^{\mathrm{T}}$ (12); in the hybridization study of Zabel et al. (12), the strain referred to as strain Los Angeles is actually strain UCLA (3; T. J. Ferguson, Ph.D. thesis, University of California at Los Angeles, Los Angeles, 1983), and strain CR1 $1^{\mathrm{T}}$ is referred to by its DSM accession number (DSM $2373^{\mathrm{T}}$ ).

The media and growth conditions which we used were the same as those used for characterization of each organism ( 2 , $5,6,9,12-14)$. For mass culture, cells were grown in a 10 -liter fermentor (1) or a 4-liter round-bottom flask. 
DNA isolation. Cultures were cooled to $4^{\circ} \mathrm{C}$, and cells were harvested by centrifugation at $5000 \times g$ for $15 \mathrm{~min}$. DNA was immediately isolated by a modification of the Marmur method (4). When harvested cells were stored as a frozen paste, DNA isolation was more difficult, perhaps because of interactions between high-molecular-weight DNA and cell debris.

G + C content of the DNA. The density of each DNA preparation was determined by ultracentrifugation in $\mathrm{CsCl}$ gradients (7); DNAs from Micrococcus lysodeikticus (Sigma Chemical Co., St. Louis, Mo.; density was assumed to be $1.731 \mathrm{~g} / \mathrm{cm}^{3}$ ) and Clostridium perfringens (Sigma; density was assumed to be $1.691 \mathrm{~g} / \mathrm{cm}^{3}$ ) were used as standards. The $\mathrm{G}+\mathrm{C}$ content of the DNA was calculated by using the formula of Schildkraut et al. (10).

DNA sequence similarity. DNA sequence similarities were determined by using the procedures of Johnson (4), including the S1 nuclease (Sigma) method for hydrolysis of singlestranded DNA; salmon sperm DNA (Sigma) was used as the reference DNA. Single-stranded DNA was labeled with $\mathrm{Na}^{125} \mathrm{I}$ (New England Nuclear Corp., Wilmington, Del.), and, after hybridization, S1 nuclease-resistant fragments were precipitated with a $20 \%(\mathrm{vol} / \mathrm{vol}) \mathrm{HCl}$ solution $(10 \mathrm{~g}$ of $\mathrm{NaH}_{2} \mathrm{PO}_{4}$ and $10 \mathrm{~g}$ of $\mathrm{Na}_{4} \mathrm{P}_{2} \mathrm{O}_{7}$ per liter of $1 \mathrm{~N} \mathrm{HCl}$ ) and collected on $0.45-\mu \mathrm{m}$ nitrocellulose filters (type HA; Millipore Corp., Bedford, Mass.). The filters were washed with three $5-\mathrm{ml}$ quantities of a $16.7 \%(\mathrm{vol} / \mathrm{vol}) \mathrm{HCl}$ solution and 2 $\mathrm{ml}$ of $95 \%$ ethanol and then dried at room temperature in a fume hood and counted with a liquid scintillation counter.

\section{RESULTS AND DISCUSSION}

We determined DNA sequence similarities among 10 strains belonging to the genera Methanogenium and Methanocorpusculum (Table 1). Although these methanogens share many taxonomically important traits, such as methanogenesis from $\mathrm{H}_{2}-\mathrm{CO}_{2}$, irregular coccoid morphology, requirement for or toleration of moderate salt concentrations during growth, and a $\mathrm{G}+\mathrm{C}$ content between 50 and $62 \mathrm{~mol} \%$, we found a great deal of phylogenetic diversity. For instance, the type species of the genus Methanogenium, Methanogenium cariaci, is only distantly related to other Methanogenium or Methanocorpusculum species. The data in Table 1 are displayed as a dendrogram in Fig. 1. Four major, distinct groups which have levels of intergroup sequence similarity of less than $10 \%$ are evident. The first group (Methanogenium marisnigri, Methanogenium bourgense, Methanogenium olentangyi, and Methanogenium thermophilicum) is physiologically the most diverse group, containing mesophiles, thermophiles, marine, and nonmarine organisms. The second group (Methanocorpusculum aggregans, Methanocorpusculum parvum, and Methanocorpusculum labreanum) contains very small mesophilic coccoid organisms isolated from anaerobic digestors. The third group contains a single species, Methanogenium tationis, which was isolated from a solfataric mud pool, and the fourth group contains the type species, Methanogenium cariaci, which is a marine organism.

Because Methanogenium aggregans is phylogenetically more closely related to Methanocorpusculum parvum than to any species of Methanogenium, we propose its transfer to the genus Methanocorpusculum, as Methanocorpusculum aggregans comb. nov. A description of the genus Methanocorpusculum has not been specifically proposed previously, so we recommend the description below.

Methanocorpusculum (Zellner, Stackebrandt, Conway de Macario, and Winter, 1987, 13). The original description of

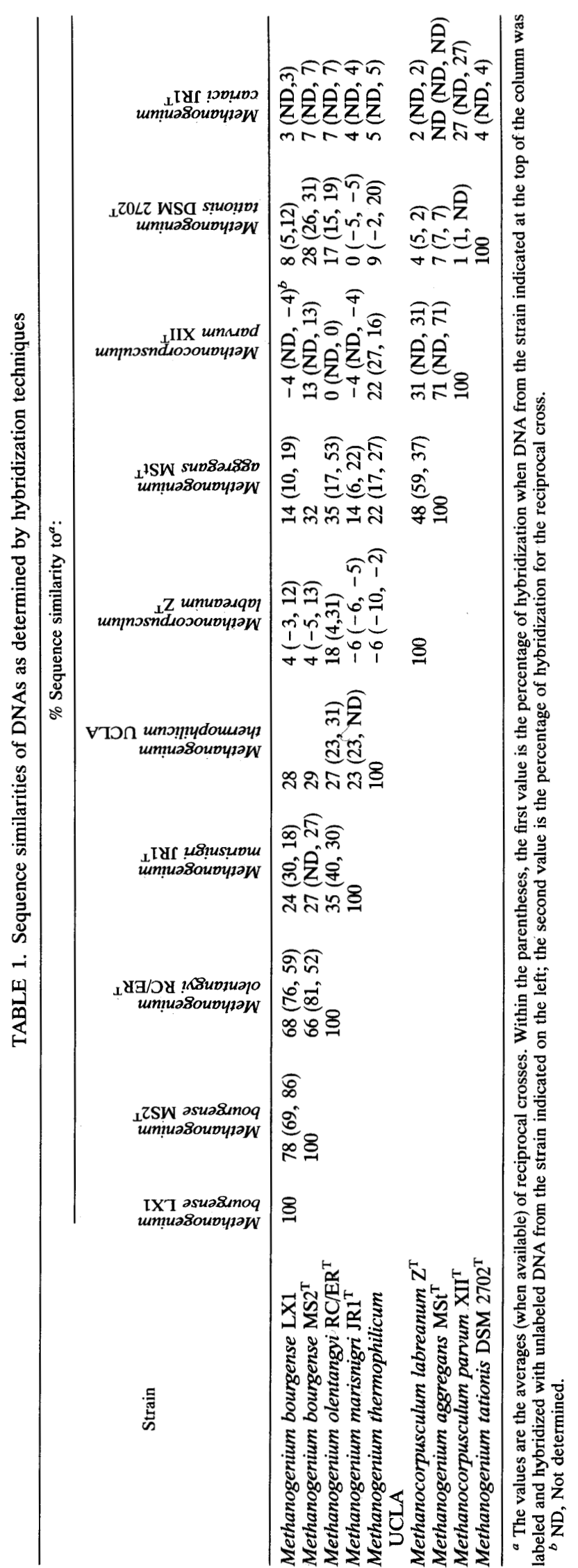




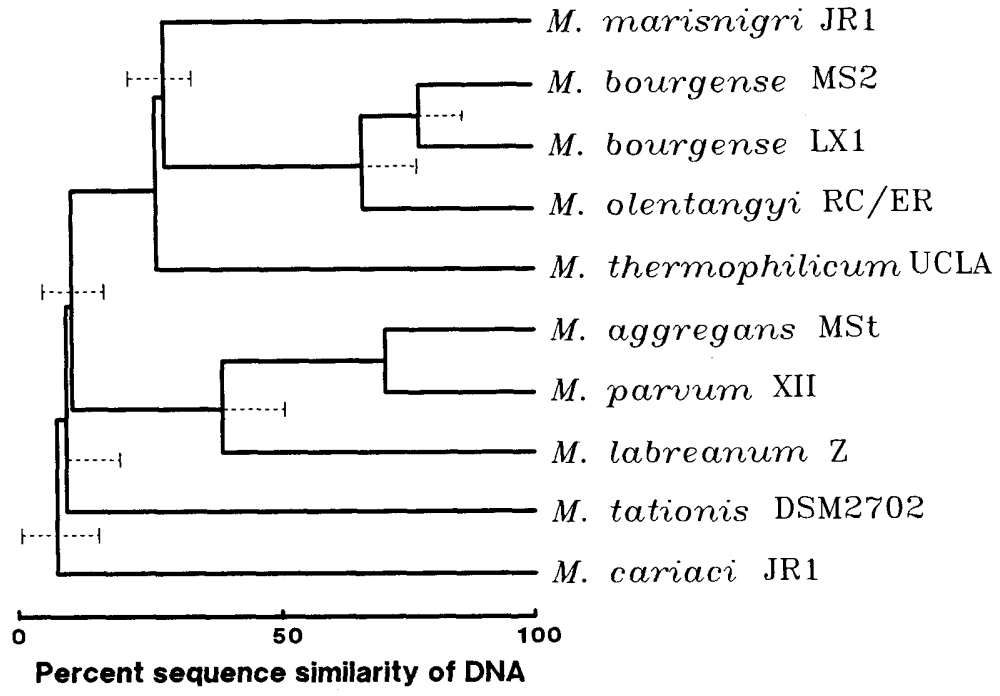

FIG. 1. Dendrogram of the phylogenetic relationships among strains of the genera Methanogenium and Methanocorpusculum. Based on DNA sequence similarities (from the values shown in Table 1), the most closely related organisms were grouped together, and the phylogenetic relationship between an organism and a group or between two groups was calculated as the average of all of the hybridization determinations between the two groups. The standard deviations are indicated by dashed lines.

Zellner et al. (13) was supplemented by data from Ollivier et al. (6) and Zhao et al. (14).

Cells are small (average diameter, $\leq 1 \mu \mathrm{m}$ ) and coccoid, with a negative Gram reaction. Sensitive to lysis in the presence of $0.3 \mathrm{~g}$ of sodium dodecyl sulfate per liter.

Catabolic substrates include $\mathrm{H}_{2}-\mathrm{CO}_{2}$ and formate; 2-propanol- $\mathrm{CO}_{2}$ may also be catabolized, but acetate, methylamines, methanol, propionate, butyrate, ethanol, and amino acids are not catabolized.

Grows most rapidly in medium with an $\mathrm{Na}^{+}$concentration of 50 to $250 \mathrm{mM}$ or more. Acetate and yeast extract or Trypticase peptones are required.

The $\mathrm{G}+\mathrm{C}$ content of the DNA is 48 to $52 \mathrm{~mol} \%$.

The type species is Methanocorpusculum parvum.

The species from the other three major groups are currently classified in the genus Methanogenium, although the lack of phylogenetic relatedness indicates that some of these should be separated from Methanogenium cariaci into new genera. However, we propose that such transfers should be postponed until additional data bearing on the phylogeny of these species are available.

\section{ACKNOWLEDGMENTS}

We thank Kevin Sowers for helpful discussions.

This work was supported by grants $480-323-4023$ and IFASGRI-FIA-MCS 2171 from the Gas Research Institute and the Institute of Food and Agricultural Sciences, University of Florida, Gainesville, respectively.

\section{LITERATURE CITED}

1. Boone, D. R., I. M. Mathrani, and R. A. Mah. 1987. $\mathrm{H}_{2}-\mathrm{CO}_{2}$ recirculation and $\mathrm{pH}$ control for growth of methanogens in mass culture. Appl. Environ. Microbiol. 53:946-948.

2. Corder, R. E., L. A. Hook, J. M. Larkin, and J. I. Frea. 1983. Isolation and characterization of two new methane-producing cocci: Methanogenium olentangyi, sp. nov., and Methanococcus deltae, sp. nov. Arch. Microbiol. 134:28-32.

3. Ferguson, T. J., and R. A. Mah. 1983. Isolation and characterization of an $\mathrm{H}_{2}$-oxidizing thermophilic methanogen. Appl.
Environ. Microbiol. 45:265-274.

4. Johnson, J. L. 1985. DNA reassociation and RNA hybridisation of bacterial nucleic acids, p. 33-74. In G. Gottschalk (ed.), Methods in microbiology, vol. 18. Academic Press, Inc. (London), Ltd., London.

5. Ollivier, B. M., R. A. Mah, J. L. Garcia, and D. R. Boone. 1986. Isolation and characterization of Methanogenium bourgense sp. nov. Int. J. Syst. Bacteriol. 36:297-301.

6. Ollivier, B. M., R. A. Mah, J. L. Garcia, and R. Robinson. 1985. Isolation and characterization of Methanogenium aggregans sp. nov. Int. J. Syst. Bacteriol. 35:127-130.

7. Preston, J. F., and D. R. Boone. 1973. Analytical determination of buoyant density of DNA in acrylamide gels after preparative $\mathrm{CsCl}$ gradient centrifugation. FEBS Lett. 37:321-324.

8. Rivard, C. J., and P. H. Smith. 1982. Isolation and characterization of a thermophilic marine methanogenic bacterium, Methanogenium thermophilicum sp. nov. Int. J. Syst. Bacteriol. 32:430-436.

9. Romesser, J. A., R. S. Wolfe, F. Mayer, E. Spiess, and A. Walther-Mauruschat. 1979. Methanogenium, a genus of marine methanogenic bacteria, and characterization of Methanogenium cariaci sp. nov. and Methanogenium maris-nigri sp. nov. Arch. Microbiol. 121:147-153.

10. Schildkraut, C. L., J. Marmur, and P. Doty. 1962. Determination of the base composition of deoxyribonucleic acid from its buoyant density in $\mathrm{CsCl}$. J. Mol. Biol. 4:430-443.

11. Zabel, H. P., H. König, and J. Winter. 1984. Isolation and characterization of a new coccoid methanogen, Methanogenium tatii spec. nov. from a solfataric field on Mount Tatio. Arch. Microbiol. 137:308-315.

12. Zabel, H. P., H. König, and J. Winter. 1985. Emended description of Methanogenium thermophilicum, Rivard and Smith, and assignment of new isolates to this species. Syst. Appl. Microbiol. 6:72-78.

13. Zellner, G., C. Alten, E. Stackebrandt, E. Conway de Macario, and J. Winter. 1987. Isolation and characterization of Methanocorpusculum parvum, gen. nov., spec. nov., a new tungsten requiring, coccoid methanogen. Arch. Microbiol. 147:13-20.

14. Zhao, Y., D. R. Boone, R. A. Mah, J. E. Boone, and L. Xun. 1989. Isolation and characterization of Methanocorpusculum labreanum sp. nov. from the LaBrea Tar Pits. Int. J. Syst. Bacteriol. 39:10-13. 